\title{
Cloud Classification in JPEG-compressed Remote Sensing Data (LANDSAT 7/ETM+)
}

\author{
Erik Borg ${ }^{1}$, Bernd Fichtelmann ${ }^{1}$ and Hartmut Asche ${ }^{2}$ \\ ${ }^{1}$ German Aerospace Center, German Remote Sensing Data Center, 17235 Neustrelitz \\ ${ }^{2}$ Potsdam University, Department of Geography, 14476 Potsdam, Germany \\ Erik.Borg@dlr.de
}

\begin{abstract}
Environmental parameters required for geo-information modelling are subject to spatial and temporal dynamics. Remote sensing data can contribute to measure those parameters. For that purpose high-accuracy classifications of remote sensing data are required which can be very timeconsuming due to the large data volumes involved. In many applications, however, the rapid provision of classified mass data is of higher priority than classification accuracy. One important focus on research and development efforts in the past years has been to optimise the automated interpretation of remote sensing data. Different investigators have shown that this interpretation can both be effective and efficient in JPEG compressed data with acceptable accuracy. This paper presents an operational processing chain for cloud detection in JPEG-compressed quick-look products of LANDSAT 7/ETM+scenes (compression ratio is 10:1). Two well-developed conventional algorithms are applied to these datasets for cloud detection. Results show that the processing chain developed is stable and produces quality results with substantially compressed mass data.
\end{abstract}

Keywords: operational cloud detection, classification, JPEG, LANDSAT 7

\section{Introduction}

Permanently increasing volumes of remote sensing data and the resulting necessity to constantly adapt storage facilities have been dealt with as early as the late 1990s. One solution to the data storage problem has been the development of lossy and lossless compression methods. Their primary objective was minimisation and handling of those data essential for thematic information mining. In this context, relevant issues, such as thematic interpretation (e.g. geo-correction, classification) based on compressed remote sensing data or achievable accuracy in relation to compression rate and quality losses, have been discussed intensively [1], [2], [3], [4].

Studies on classification accuracy of compressed remote sensing imagery have used multispectral data which were subjected to a step-wise compression of $5 \%$ in an ascending order [1], [2]. Compressed and un-compressed reference data sets were subsequently classified by supervised as well as un-supervised classifications. The investigations revealed that classification accuracy decreases in the interval [1:1; 35:1] from $95 \%$ to $60 \%$. At compression ratios higher than 35:1 the decrease is even more 
marked compared against the original image data. Contrasting investigations, such as [3] and [4], have shown that JPEG compression effects some kind of data homogenisation. As a result the so-called salt-and-pepper-effect in noisy data is reduced significantly so that better classification results can be achieved.

This work deals with the development of a cloud detection algorithm for datareduced JPEG-quick-look-data of LANDSAT 7/ETM+-scenes at a compression ratio of 10:1. Considering the results of [1], [2] a classification accuracy of some $70 \%$ is feasible.

\section{Material and Methods}

\subsection{Quick-look and Metadata of the LANDSAT 7 / ETM+}

Investigations presented here are based on 2,480 quick-look ${ }^{1}$ and metadata ${ }^{2}$ from the period of 2000 to 2003. In a first step the quick-look data are pre-processed. The radiometric correction of the data is based on a simple linear stretch of raw data based on predefined look-up tables. Geometric pre-processing includes, i.a., a data reduction [5]:

- Bands 1-5, 7: $6 \times 6$ pixels of the original data are reduced to 1 selected pixel,

- Thermal band 6: $3 \times 3$ pixels are reduced to 1 selected pixel.

- Panchromatic band: 12 x 12 pixels are reduced to 1 selected pixel.

As a consequence, all bands have a ground resolution of $180 \mathrm{~m}$. Following data reduction the quick-look data are stored in the JPEG format. As has been mentioned the JPEG compression method is lossy. Hence quality and information losses as well as artefacts are possible at a compression too strong. A detailed description of the procedure can be found in [6], [7]. The data available for this study were compressed with a ratio of 10:1 [5]. Although the level of compression depends on the image content of a remote sensing scene, this represents a JPEG quality metric Q-factor of 35 [2]. Consequentially, quality loss is of significance for thematic post-processing of these data.

\subsection{Classification algorithms}

Classification generally aims at labeling of feature properties to corresponding predefined property scale. For that purpose supervised and unsupervised procedures are used. Both classification strategies require interactive operation of an interpreter to, e.g., define training targets or interpretation schemes. In contrast, automatic

\footnotetext{
${ }^{1}$ Quick-look data are preview images derived from original remote sensing data.

${ }^{2}$ Metadata describes remote sensing data (e.g. satellite mission, orbit, track, frame)
} 
classification procedures operate on pre-defined schemes based on extensive analysis to derive a representative attribution list.

With NASA-ACCA (NASA - National Aeronautics and Space Administration) [8], [9] and ACRES-ACCA-procedure (National Earth Observation Group - previously known as ACRES) [10] two established Automatic Cloud Cover Assessment (ACCA) procedure are used for cloud detection within LANDSAT-data. The NASA-procedure is integrated in the operative processing chain of the LANDSAT Ground station at EROS Data Center in Sioux Falls [8], [9]. The ACRES-procedure was developed to minimise personal and time consuming data quality analysis as well as to minimise the subjectivity of operator evaluations in the operative LANDSAT-processing chain of ACRES [10].

NASA-ACCA-Procedure: The cloud detection algorithm uses radiometric corrected data of LANDSAT bands 2 to 6 [9]. Bands 2 to 5 are calibrated and converted to spectral reflectance. The data of band 6 are transformed into temperature values. The automatic NASA-procedure is a two-level procedure. Level 1 is based on an eight conservative filter-cascade for pixel-wise cloud detection to derive a temporary cloud mask. Level 2 uses the classification results of level 1 processing as input. Subsequently, a confident thermal cloud signature is derived for verified cloud pixels by means of the cloud-pixels detected. For this reason data of band 6 (thermal band) are exclusively statistically evaluated. To differentiate snow and clouds the snow area within the image matrix will be calculated. For that purpose a corresponding filter is used. A quality control procedure selecting misclassified pixels is integrated in this processing level. A detailed description of the NASA-procedure is given in [9].

ACRES-ACCA-Procedure: Pre-processing of the ACRES procedure includes different processing levels. First, the effective spatial resolution of the data is reduced to $240 \mathrm{~m}$. The result is a reduction of the required processing duration and the oppression of isolated clouds at low height $(<200 \mathrm{~m})$. Subsequent processing of the data is carried out in segments of $3 \mathrm{~km} \times 3 \mathrm{~km}$. Once clouds are identified in one of the segments, this segment is marked as cloudy. Additionally all seven bands are calibrated and converted to reflectance. The data of the thermal band are converted to radiation temperatures. The following description of the processor is based on [10]. The ACRES procedure uses 12 filters to derive cloud masks. An additional filter is required to distinguish cold clouds from warm surface features [10]. The method is only based on a processing cascade unlike the NASA-procedure. To distinguish cloud and non-cloud features in the data special band thresholds or ratios of different spectral band combinations are used.

\section{Method}

Data quality can be defined as ratio of cloud-pixel-number to the total number of pixels in an assessment unit (e.g. quadrant, scene). If different cloud detection algorithms are exchanged for one another, the algorithms can be subjected to comparative analysis under standardised conditions. 


\section{E. Borg et al.}

At implementation of additional algorithms the possibility for derivation of value added data products insists on basis of quick-look-data. Mass data processing under realistic conditions requires a solution of the organisational problems of demand driven data supply as well as of the functional problems of data processing as a prerequisite. Moreover, the processing chain includes 7 modules (Fig. 1) for provision of data for processing JPEG-compressed remote sensing data and/or for coordination of information processes.

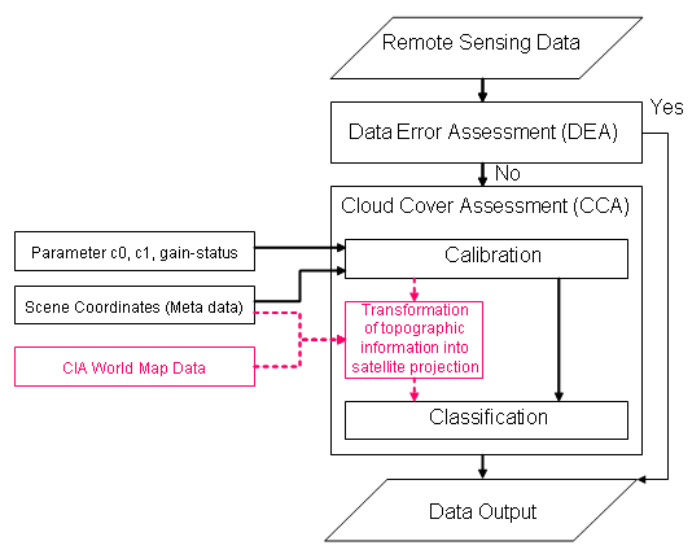

Fig. 1. Scheme of the processing chain for the determination of the data quality of LANDSAT 7/ETM+ data

\subsection{Pre-processing step}

Conversation to Top-of-Atmosphere reflectance: With sensor-specific calibration coefficients (offset $c_{0}$, gain $c_{1}$ ) digital numbers $(D N)$ recorded can be transformed into measured at sensor radiance $L\left(\lambda_{k}\right)[11]$ :

$$
L\left(\lambda_{k}\right)=c_{0}\left(\lambda_{k}\right)+c_{1}\left(\lambda_{k}\right) D N\left(\lambda_{k}\right)
$$

$c_{0}\left(\lambda_{k}\right)$ and $c_{1}\left(\lambda_{k}\right)$ are the calibration coefficients of band $k$ of LANDSAT 7/ETM+. The relation between planetary top-of-atmosphere reflectance $\rho_{p}$ and the digital number of a pixel $(D N)$ in a specified band $k$ can be expressed by equation 2 [13], [14]:

$$
\rho_{\rho}=\left(\pi L\left(\lambda_{k}\right) d^{2}\right) /\left(E_{S}\left(\lambda_{k}\right) \cos \theta_{S}\right)
$$

$L\left(\lambda_{k}\right)$ is the spectral radiance of band $k$ at sensor's aperture $\left[W /\left(m^{2} s r \mu m\right)\right]$, $E_{S}\left(\lambda_{k}\right)$ is the mean exoatmospheric solar irradiance of band $k\left[W /\left(m^{2} \mu m\right)\right], d$ is the Earth-Sun distance [Astronomical Units], and $\theta_{S}$ is the solar zenith angle [degrees]. 


\section{Cloud Classification in JPEG-compressed Remote Sensing Data (LANDSAT 7/ETM+)}

Sensors like LANDSAT 7/ETM+ can switch the gain of bands to control the sensitivity of the sensor. Parameters for deriving the planetary top-of-atmosphere reflectance $\rho_{p}$ are represented in Table 1.

Table 1. Solar spectral irradiances and sensor-specific calibration coefficients (c0, c1) according to LANDSAT-bands [12] ${ }^{3},{ }^{4}$

\begin{tabular}{|c|c|c|c|c|c|c|}
\hline Band & $\mathbf{1}$ & $\mathbf{2}$ & $\mathbf{3}$ & $\mathbf{4}$ & $\mathbf{5}$ & $\mathbf{7}$ \\
\hline $\begin{array}{c}\text { Sol } \\
{\left[\mathrm{W} /\left(\mathrm{m}^{2} \mu \mathrm{m}\right)\right]}\end{array}$ & 1969 & 1840 & 1551 & 1044 & 225,7 & 82,07 \\
\hline Low Gain \\
\hline $\begin{array}{c}c_{0}{ }^{6} \\
{\left[\mathrm{~W} /\left(\mathrm{m}^{2} \mathrm{sr} \mu \mathrm{m}\right)\right]}\end{array}$ & -6.2 & -6.4 & -5.0 & -5.1 & -1.0 & -0.35 \\
\hline $\begin{array}{c}c_{1}{ }^{7} \\
{\left[\mathrm{~W} /\left(\mathrm{m}^{2} \mathrm{sr} \mu \mathrm{m}\right)\right]}\end{array}$ & 1.1760 & 1.2051 & 0.9388 & 0.9654 & 0.1905 & 0.0668 \\
\hline High Gain \\
$\begin{array}{c}c_{0}{ }^{8} \\
{\left[\mathrm{~W} /\left(\mathrm{m}^{2} \mathrm{sr} \mu \mathrm{m}\right)\right]}\end{array}$ & -6.2 & -6.4 & -5.0 & -5.1 & -1.0 & -0.35 \\
\hline $\begin{array}{c}c_{1}{ }^{9} \\
{\left[\mathrm{~W} /\left(\mathrm{m}^{2} \mathrm{sr} \mu \mathrm{m}\right)\right]}\end{array}$ & 0.7757 & 0.7956 & 0.6192 & 0.6372 & 0.1257 & 0.0437 \\
\hline
\end{tabular}

The Earth-Sun-distance can be calculated approximately using equation 3 [15].

$$
d=1+0.0167 \sin [(\pi(\text { Doy }-93.5)) / \text { Loy }] \text {. }
$$

Doy is the Day of year, and Loy the Length of year (365 or 366 in the leap year).

Conversation to at sensor brightness temperature: Band 6 of LANDSAT 7/ETM+ covers the wavelength from $10.4 \mu \mathrm{m}$ to $12.5 \mu \mathrm{m}$ recording emitted thermal radiation of the Earth. According to equation 4 digital numbers recorded of band 6 $(D N)$ can be transformed into effective measured temperatures $T$ [12].

$$
T=K_{2} / \ln \left(\left(K_{1} / L(\lambda)\right)+1\right) \text {. }
$$

$\mathrm{T}$ is the effective at-sensor brightness temperature $[\mathrm{K}], L(\lambda)$ the spectral radiance at the sensor's aperture $\left[W /\left(m^{2} s r \mu m\right)\right], \quad K_{1}$ the calibration constant 1 $\left[666,09 \cdot \mathrm{W} /\left(\mathrm{m}^{2} \mathrm{sr} \cdot \mu \mathrm{m}\right)\right]^{10}$, and $K_{2}$ the calibration constant $2[1282,71 \mathrm{~K}]^{11}$.

${ }^{3}$ http://landsathandbook.gsfc.nasa.gov/cpf/prog_sect9_2.html (last access 04.01.2012).

4 http://landsathandbook.gsfc.nasa.gov/data_prod/prog_sect11_3.html (last access 04.01.2012).

${ }^{5}$ LANDSAT-Handbook: chapter 9.2.4 Table 9.1 Solar Spectral Irradiances.

${ }^{6}$ LANDSAT-Handbook: chapter 11.3.1 Conversation to Radiance

${ }^{7}$ LANDSAT-Handbook: chapter 11.3.1 Table 11.2, $\mathrm{c}_{1}=\left(\mathrm{L}_{\max }-\mathrm{L}_{\min }\right) /\left(\mathrm{Q}_{\text {calmax }}-\mathrm{Q}_{\text {calmin }}\right)$.

${ }^{8}$ LANDSAT-Handbook: chapter 11.3.1 Conversation to Radiance

${ }^{9}$ LANDSAT-Handbook: chapter 11.3.1 Table 11.2, $\mathrm{c}_{1}=\left(\mathrm{L}_{\max }-\mathrm{L}_{\min }\right) /\left(\mathrm{Q}_{\text {calmax }}-\mathrm{Q}_{\text {calmin }}\right)$.

${ }^{10}$ LANDSAT-Handbook: chapter 9.2.4, Table 9.2 ETM+ Thermal Constants.

${ }^{11}$ LANDSAT-Handbook: chapter 9.2.4, Table 9.2 ETM+ Thermal Constants. 


\section{Results and Discussion}

\subsection{Processor adaption (Europe)}

The cloud classification algorithms (NASA- and ACRES-procedure) were tested for their applicability to JPEG-compressed quick-look-data and acquisition conditions prevalent in Europe.

Table 2. Basic ACRES-filter-configuration and modified configuration of ACRES-procedure (design, threshold values, relations and results)

\begin{tabular}{||c|c|c|c|c|c|c||}
\hline \hline Filter & $\begin{array}{c}\text { Filter } \\
\text { definition }\end{array}$ & $\begin{array}{c}\text { Re- } \\
\text { lation }\end{array}$ & $\begin{array}{c}\text { ACRESS } \\
\text { threshold }\end{array}$ & $\begin{array}{c}\text { Modified } \\
\text { threshold }\end{array}$ & Result & Input for filter \\
\hline 1 & $B 6$ & $<$ & $253 \mathrm{~K}$ & $253 \mathrm{~K}$ & Cold cloud & 2 \\
\hline 2 & $B 4$ & $<$ & 55 & 50 & Dark objects & 3 \\
\hline 3 & $B 4 / B 7$ & $>$ & 2.0 & 5.5 & Snow e.g. & 4 \\
\hline 4 & $B 4 / B 5$ & $>$ & 3.1 & 4.5 & Snow & 5 \\
\hline 5 & $B 1 / B 7$ & $>$ & 4,5 & 5.2 & Snow & 6 \\
\hline 6 & $B 1$ & $</>$ & $80 / 240$ & 60 & Land/Sand & 7 \\
\hline 7 & $B 5 / B 7$ & $<$ & 1.3 & 0.9 & Salt & 8 \\
\hline 8 & $B 2 / B 3$ & $<$ & 0.9 & 0.6 & Salt & 9 \\
\hline 9 & $B 4$ & $</>$ & $140 / 210$ & $30 / 250$ & Sand & 10 \\
\hline 10 & $B 1 / B 2$ & $<$ & 1.03 & 0.73 & Sand & 11 \\
\hline 11 & $B 7$ & $<$ & 80 & 20 & Snow / Salt & 12 \\
\hline 12 & $B 1 / B 3$ & $<$ & 0.9 & 0.6 & Land & 13 \\
\hline 13 & $B 6$ & $<$ & $170-180$ & 310 & No & Cloud mask \\
\hline \hline
\end{tabular}

While the NASA-procedure could directly be applied to the quick-look-data without quality restriction, the ACRES-procedure required adaptation to recording conditions of Central Europe. That is why different data sets were used. The results were checked visually for the iterative optimisation of the filter threshold values. The resulting new threshold values are listed in Table 2. The absolute error $\varepsilon_{i}$ was calculated for each quadrant. The respective interpreter vote was accepted as true value $x$ and the results of the original ACRES and modified ACRES-procedures were defined as measurements $x_{1}, x_{2}, \ldots x_{i}$. The absolute error $\varepsilon_{i}$ can be written as follows:

$$
\varepsilon_{i}=x_{i}-x
$$

The absolute error $\varepsilon_{i}$ of classification results is shown before (Fig. 2a) and after modification (Fig. 2b). The interpretation of negative skewness of frequency distribution (Fig. 2a) suggests that clouds are underestimated when using the original ACRES-procedure. Modification of the algorithm thresholds yields skewness and frequency distribution curves (Fig. 2b) that indicates a more stable and more precise result when employing the modified ACRES-procedure. Differences that occur between assessment results by the automatic procedure and by interpreter can partly be explained by the subjectivity of interpreters [16]. 
a)

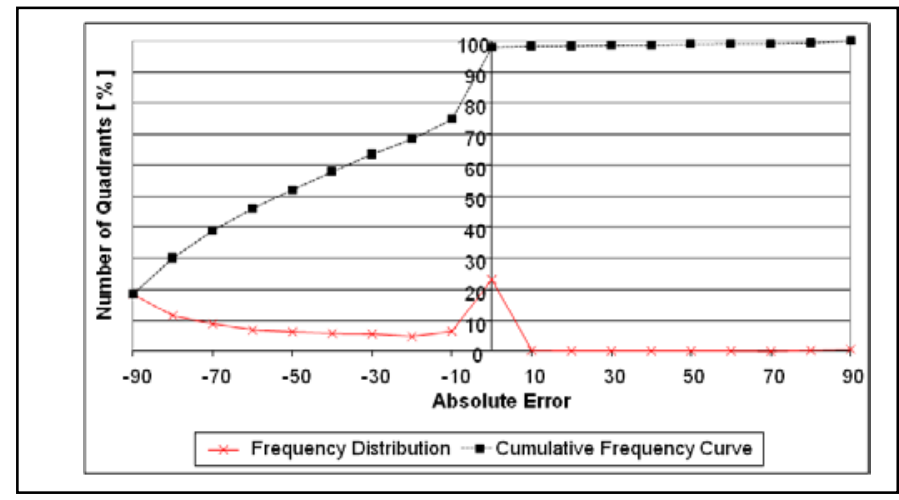

b)

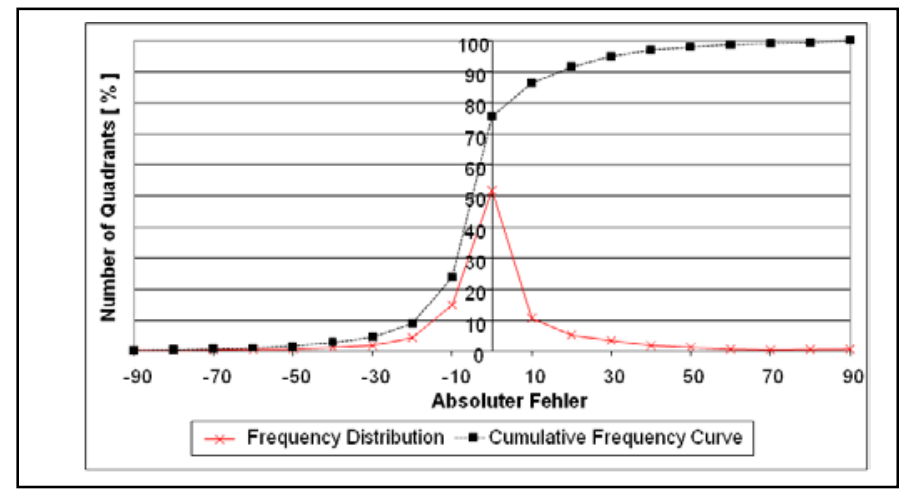

Fig. 2. Comparison of a) original ACRES- and b) modified ACRES-procedure

\subsection{Validation of classification power}

Both NASA-ACCA and modified ACRES-ACCA classification procedures assign each pixel either as "cloud" or "non-cloud". In this binary classification unclassified pixels are impossible.

The classification accuracy of both procedures is investigated on the basis of a pixel by pixel cloud mask comparison (Tab. 3). For that purpose two classes are defined. Pixels classified identically by both procedures as "cloud" or "cloud free" are labeled as "identically classified". The remaining pixels are labeled as "differently classified". Fig. 3 shows exemplarily a quick-look image (above; left site) with its auxiliary data (above; right site) in comparison to the overlaid classification results of NASA- and ACRES-algorithms (below; left site) and the interpretation key of the mask (below; on right site). The visual control of the classification allows assessing the classification accuracy of both classification procedures. 
E. Borg et al.

Table 3. Confusion matrix for the entire classified data set (NASA-procedure (Reference) and ACRES-procedure (Classification))

\begin{tabular}{|c|c|c|c|c|}
\hline \multicolumn{5}{|c|}{ NASA-ACCA (Reference) } \\
\hline & Cloud free & 1260119847 & Cloud & Total \\
\cline { 2 - 5 } & Cloud & 99051006 & 163828367 & 1423948214 \\
\cline { 2 - 5 } ACRES- \\
ACCA & Total & 1359170853 & 957000780 & 1056051786 \\
\cline { 2 - 5 } & & 1120829147 & 2480000000 \\
\hline
\end{tabular}

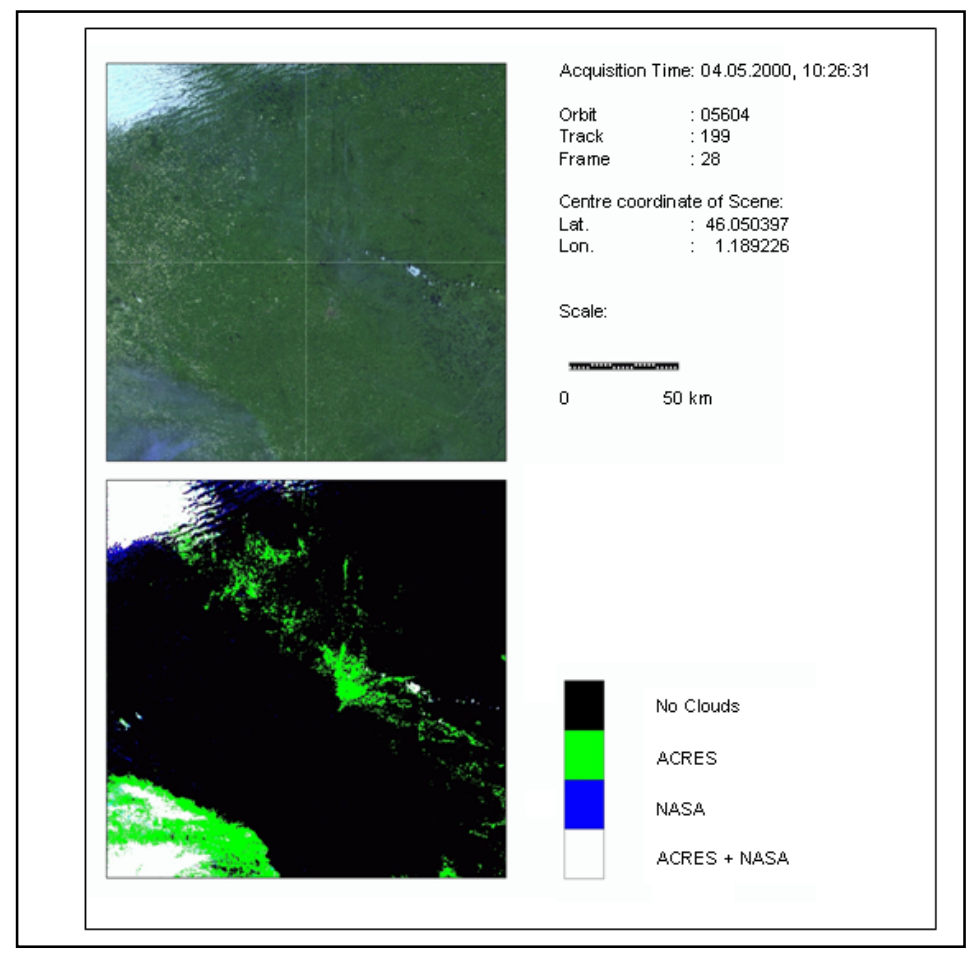

Fig. 3. Comparative analysis of classification results of the modified ACRES procedure overlaid by the classification result of NASA procedure

The qualitative assessment by visual control is complemented by a quantitative analysis. Accuracy of a classification can be assessed by a confusion matrix [17]. Hence a confusion-matrix is calculated pixel-wise for all cloud masks to obtain a classification accuracy statement of both procedures which allows further analysis. Table 3 shows the confusion matrix; and Table 4 shows the quality indices obtained from the confusion matrix. Additionally the Kappa coefficient $K C$ (equation 6) and the overall accuracy $O A$ (equation 7) are calculated [18].

$$
K C=\left(n \sum_{i=1}^{k} n_{i i}-\sum_{i=1}^{k} n_{i+} n_{+i}\right) /\left(n^{2}-\sum_{i=1}^{k} n_{i+} n_{+i}\right) .
$$




$$
O A=\sum_{i=1}^{K} n_{i i} / n
$$

$k$ is the number of valuation classes, $n$ is the number of reference pixels. $n_{i i}$ are the elements of the principle diagonal, $n_{i+} n_{+i}$ are the elements of the matrix above and below the principle diagonal. The mean overall accuracy of method comparison for the NASA and ACRES procedures is calculated from the overall accuracies of the classified single quick-look data. In addition the corresponding standard deviation is calculated. The mean overall accuracy is 89.40 percent and standard deviation is 12.60 percent.

Table 4. Kappa -Coefficient, Overall Accuracy, Users Accuracy, Producer Accuracy of overall comparison

\begin{tabular}{|c|c|c|c|c|c|}
\hline \multirow{2}{*}{$\begin{array}{c}\text { Kappa- } \\
\text { Coefficient }\end{array}$} & \multirow{2}{*}{$\begin{array}{c}\text { Overall } \\
\text { Accuracy } \\
{[\%]}\end{array}$} & \multicolumn{2}{|c|}{$\begin{array}{c}\text { Users Accuracy [ \% ] } \\
\text { ACRES-ACCA }\end{array}$} & \multicolumn{2}{|c|}{$\begin{array}{r}\text { Producer Accuracy [ \% ] } \\
\text { NASA-ACCA }\end{array}$} \\
\cline { 3 - 6 } & & Cloud free & Cloud & Cloud free & Cloud \\
\hline 0,78 & 89,40 & 92,71 & 85,38 & 88,49 & 90,62 \\
\hline
\end{tabular}

The Kappa coefficient (scaled at interval $[-1.0,1.0]$ ) of the combined NASA and ACRES procedures over all quick look data is 0.78 . A validation of the classification accuracy can be carried out by using the valuation scale by [19]. Kappa coefficients in interval $[0.81,1.00]$ are interpreted as "almost perfect" and in interval [0.61, 0.80] as "substantial". The overall accuracy values show that both algorithms can be applied to data-reduced quick-look products and to produce acceptable accurate and stable classification results.

The presented investigations demonstrate that a primarily physical evaluation of remote sensing data produces stable and accurate results for data-reduced JPEGcompressed quick-look data. Further examinations will show whether more complex evaluations are possible on the basis of reduced remote sensing datasets.

Acknowledgements. This study was made possible by substantial data sponsoring from ESA. In particular, the authors would like to thank Drs. Berutti, Biasutti, and Pitella for their interest in the investigations presented. The authors would also like to thank the ground station operation team at DLR Neustrelitz.

\section{References}

1. Lam, K. W.-K., Lau, W.-L., Li, Z.-L. (1999): Effects of JPEG Compression on Accuracy of Image Classification. GIS developments, Proceedings, ACRS.- 3 p. URL: http://www.gisdevelopment.net/aars/acrs/1999/ts11/ts11009.shtml (last access: 13.08.2005)

2. Lau, W.-L., Li, Z.-L., Lam, K.W.-K. (2003): Effects of JPEG compression on image classification. Int. J. Remote Sensing, 24(7), 1535-1544

3. Zabala, A., Pons, X., Masó, J., García, F., Aulí, F., Serra, J. (2005): Evaluation of JPEG and JPEG2000 effects on remote sensing image classification for mapping natural areas. WSEAS Transactions on Information Science and Applications, 6(2), 717-725 


\section{E. Borg et al.}

4. Zabala, A., Pons, X., Diaz-Delgado, R., García-Vílchez, F., Aulí, F., Serra-Sagristà, J. (2006): Effects of JPEG and JPEG2000 lossy compression on remote sensing image classification for mapping crops and forest areas. 26th International Geoscience and Remote Sensing Symposium. IEEE Press, Denver, Colorado, USA, August 2006. IEEE

5. Spaventa, V. D. (2004): (personal communication)

6. Lammi, J., Sarjakoski, T. (1995): Image Compression by the JPEG algorithm. Photogrammetric Engineering and Remote Sensing, 61, 1261 - 1266

7. Lane, T. (1999): JPEG image compression FAQ, part 1 and part 2. URL: http://www.faqs.org/faqs/jpeg-faq/ (last access: 20.02.2012)

8. Irish, R. (1998): Automatic Cloud Cover Assessment (ACCA) LANDSAT 7 ACCA. Goddard Space Flight Center. LANDSAT -7 Science Team Meeting December 1-3, 1998, http://landsathandbook.gsfc.nasa.gov/pdfs/ACCA_slides.pdf (last access: 20.02.2012).

9. Irish, R. (2000): LANDSAT 7 Automatic Cloud Cover Assessment. Sylvia, S. S., Descour, M. R. (eds.) Algorithms for Multispectral, Hyperspectral, and Ultraspectral Imagery VI, Proceedings of SPIE, vol. 4049, 348 - 355

10. Xu, Q., Wu, W. (2003): ACRES Automatic Cloud Cover Assessment of LANDSAT 7 Images. Spatial Sciences Conference 2003 - Spatial Knowledge without Boundaries, Canberra, September 23-26, 2003, p. 10

11. Slater, P. N., Biggar, S. F., Holm, R. G., Jackson, R. D., Mao, Y., Moran, M. S., Palmer, J. M., Yuan, B. (1987): Reflectance and Radiance-Based Methods for the In-Flight Absolute Calibration of Multispectral Sensors. Remote Sens. Environ., 22(1), 11-37

12. NASA (2011): http://landsathandbook.gsfc.nasa.gov/cpf/prog_sect9_2.html (Last access: 04.01.2012)

13. Markham, B.L., Barker, J.L. (1985): Spectral characterization of the LANDSAT Thematic Mapper Sensors. Int. J. Remote Sensing, 6(5), 697-716

14. Chander, G., Markham, B.L., Helder, D.L. (2009). Summary of Current Radiometric Calibration Coefficients for Landsat MSS, TM, ETM+, and EO-1 ALI Sensors. Remote Sens. Environ. 113, 893-903. URL: http://landportal.gsfc.nasa.gov/Documents/ Landsat_Calibration_Summary.pdf (last access: 20.02.2012)

15. Gurney, R. J., Hall, D. K. (1983): Satellite-derived surface energy balance estimates in the Alaskan Sub-Arctic. J. Clim. Appl. Meteor., 22(1), 115-125

16. Borg, E., Fichtelmann, B., Asche, H.: Data Usability Assessment for Remote Sensing Data - Accuracy of Interactive Data Quality Interpretation. In: Beniamino Murgante, Osvaldo Gervasi, Andrés Iglesias, David Taniar, Bernady O. Apduhan (Hrsg.): ICCSA 2011, Part II, LNCS 6783, Springer-Verlag Berlin Heidelberg 2011, 366-375 (2011)

17. Congalton, R.G.: A Review of Assessing the Accuracy of Classifications of Remotely Sensed Data. Remote Sens. Environ. 37, 35-46 (1991)

18. Congalton, R.G.; Green, K.: Assessing the accuracy of remotely sensed data: principles and practices. Boca Raton, FL: Lewis Publishers. 137 p. (1999)

19. Landis, J.R.U., Koch, G.G.: The measurement of observer agreement for categorical data. Biometrics, 33, 159 - 174 (1997) 